Diabetologia 10,601-606 (1974)

(C) by Springer-Verlag 1974

\title{
Morphologic Changes in the Aorta of the Diabetic Chinese Hamster*
}

\author{
H.L. McCombs, G.C. Gerritsen, W.E. Dulin, and A.V. Chobanian \\ Laboratory of Biochemical Pathology, Boston University Medical Center, Boston, Massachusetts 02118 USA
}

\begin{abstract}
Summary. Light and electron microscopic observations of the thoracic aortas of hypercholesterolemic, diabetic Chinese hamsters compared with normocholesterolemic, nondiabetic matched controls revealed significant ultrastructural changes in the diabetic animals. Endothelial cells frequently contained osmiophilic lipid droplets. Smooth muscle cells were identified in the intima and the adjacent extracellular space of the intima contained abundant electron dense, amorphous' material suggestive of elastin or fragmented internal elastic lamella. Calcium
\end{abstract}

deposits were present in the media and surrounded by collagen fibers and pale, amorphous material consistent with ground substance. Those changes were not observed in nondiabetic Chinese hamsters and may represent significant alterations that predispose the aorta to more extensive pathologic changes.

Key words: Chinese hamster, diabetes mellitus, cholesterol, aorta, endothelium, intima, smooth muscle cell, elastic tissue, collagen, calcium.
Although ultrastructural studies of the pancreas in various diabetic animal models are well documented $[7,8,9,10,11,15]$ virtually no information is available on possible associated arterial changes $[3,11]$. It is well known that diabetes mellitus in humans is a predisposing factor in the development of atherosclerosis and characteristic basal lamina thickening in small vessels has been identified by electron microscopy [18] but the underlying mechanism has not been clarified $[12,16$, $17,18]$. Obviously, a prospective study in human diabetics attempting to correlate metabolic with morphologic changes in large vessels such as the coronary arteries and aorta is not feasible.

The Chinese hamster (Cricetulus griseus) is an animal model having many of the characteristics of human diabetes mellitus $[2,4,5]$ and the development of the disease appears to be controlled by several recessive genes [1]. Initial studies have revealed hyperlipemia and increased cholesterol content in the aortic wall associated with morphologic changes [3]. The present preliminary report describes significant ultrastructural changes in the aorta of hypercholesterolemic, diabetic Chinese hamsters.

\section{Materials and Methods}

Adult male and female diabetic Chinese hamsters ranging in age from 12 to 33 months were obtained from the Upjohn colony following repeated determinations for plasma glucose, urine glucose and ketones, plasma insulin, and total serum cholesterol levels. A nondiabetic sibling of the same sex and approximately the same age and body weight served as a matched. control for each diabetic hamster in the study. All animals were caged individually and received Purina Mouse Breeder Chow ad libitum.

\footnotetext{
* Supported by USPHS Grant HL-12869
}

Plasma glucose concentrations were analyzed on $0.05 \mathrm{ml}$ of blood by the Auto-Analyzer microglucose procedure. Plasma insulin values were determined on $0.1 \mathrm{ml}$ of plasma by a double antibody method using quinea pig anti-insulin serum [19]. Urinary giucose levels were estimated using Testape ${ }^{\circledR}$ and urinary ketones by using Ketostix ${ }^{\circledR}$. Serum total cholesterol values were determined by a method described previously [3].

The hamsters were not fasted prior to sacrifice and were killed by an overdose of ether. The descending thoracic aorta was dissected free in the unopened state and immersed at once in $3 \%$ glutaraldehyde buffered to $\mathrm{pH} 7.3$ with $0.1 \mathrm{M}$ phosphate buffer at room temperature. Each aortic segment was agitated with care, resulting in removal of most of the blood from the lumen. After $2 \mathrm{~h}$ of glutaraldehyde fixation, 4 to 6 transverse, round, cross-sections were cut from the mid-portion of each aorta. Individual sections were $3 \mathrm{~mm}$ in average length to facilitate proper orientation during embedding. Care was taken not to touch the endothelial surface at any time during initial dissection, subsequent processing or handling with forceps, and no sections were taken near previously cut margins.

Tissue blocks were immersed in $0.1 \mathrm{M}$ phosphate buffer at $\mathrm{pH} 7.3$ for several hours, postfixed for $1 \mathrm{~h}$ at room temperature in $1 \%$ osmium tetroxide buffered with $0.1 \mathrm{M}$ phosphate, rinsed in distilled water, dehydrated in ethanol $(50 \%, 75 \%, 95 \%$, and absolute for $15 \mathrm{~min}$ each), immersed for $2-5 \mathrm{~min}$ in propylene oxide, and left overnight uncapped in a well-ventilated hood in a mixture of $50 \%$ propylene oxide and $50 \%$ Epon 812. The round sections of the aorta were embedded on end in size $\# 00$ gelatin capsules (Eli Lilly) containing Epon 812 and put in an incubator at $60^{\circ} \mathrm{C}$ for $48 \mathrm{~h}$ to polymerize.

Sections were cut of every block using glass and. diamond knives on Porter-Blum I ultramicrotomes. 
Thick sections of each block were mounted on glass slides, stained with $0.5 \%$ toluidine blue buffered at $\mathrm{pH} 11$ with sodium borate, permanently mounted in permount, and examined by light microscopy. Ultrathin sections were mounted on bare 200-mesh copper grids and stained with $5 \%$ aqueous uranyl acetate followed by lead citrate [13]. Sections were examined and electron micrographs taken with an Hitachi 11C electron microscope at an acceleration voltage of 50 kilovolts.

\section{Results}

Light microscopic examination of epon embedded thick sections of descending thoracic aorta failed to reveal any significant differences between diabetic and nondiabetic hamsters. Elastic lamellae were seen with alternating layers of smooth muscle cells. The endothelium appeared closely adherent to the internal elastic lamella and no areas of intimal thickening were identified (Fig. 1).

Electron microscopic examination revealed that endothelial cells of diabetic animals often contained osmiophilic lipid droplets, had highly developed Golgi complexes, a basement membrane or lamina of uniform thickness, and in most areas an underlying internal elastic lamella that appeared normal (Fig. 2). Lipid droplets were not seen in endothelial cells of nondiabetic control animals. Microtubules and Palade granules appeared to be increased in endothelial cells of diabetic compared to nondiabetic controls, but this finding was not consistent. Smooth muscle cells were identified in the intima of diabetic animals in approximately one-third of the sections. Abundant electron dense masses of amorphous material sug-

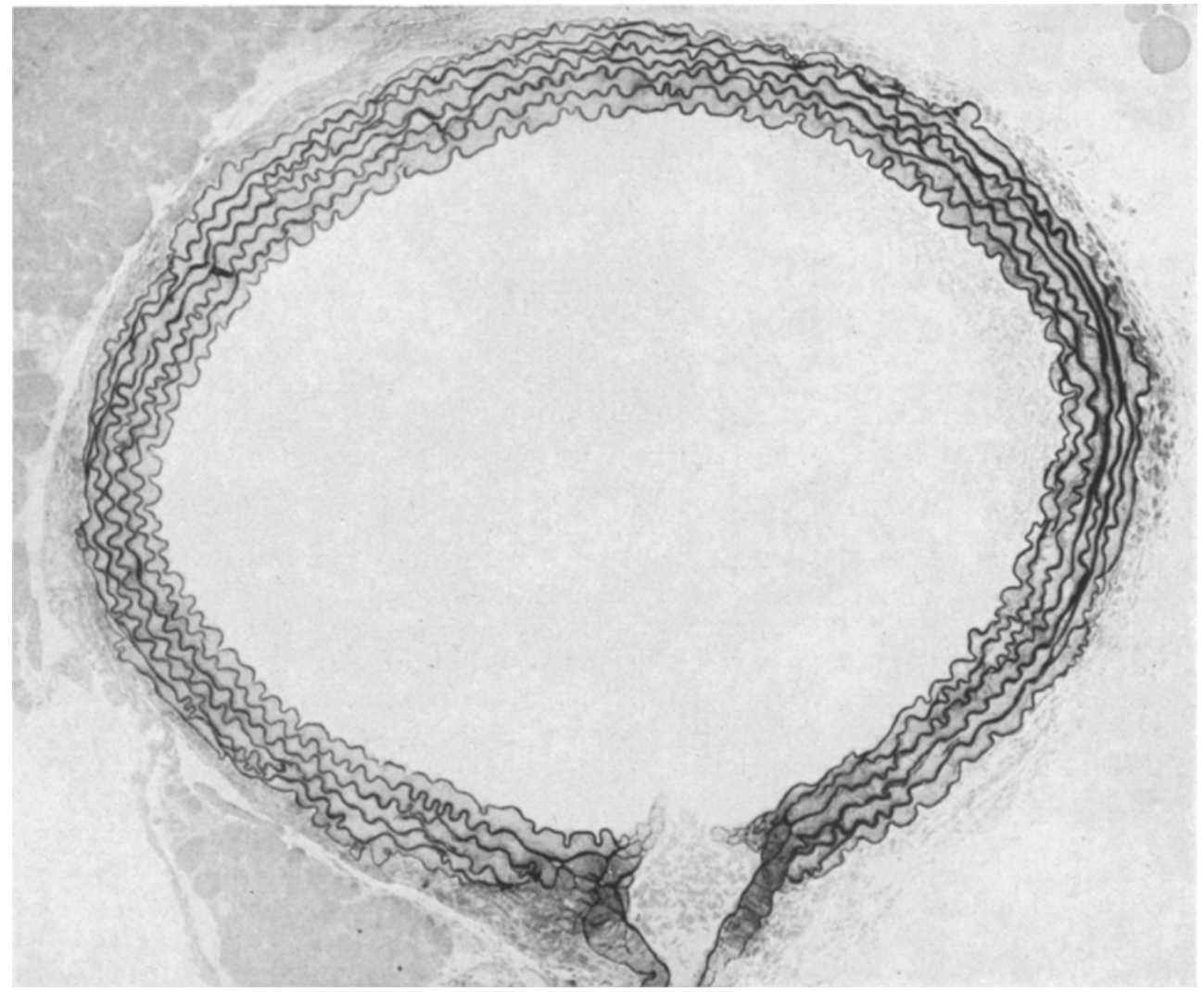

Fig. 1. Descending thoracic aorta from a 24 month old diabetic Chinese hamster. Elastic lamallae are fairly uniform with alternating layers of smooth muscle cells. Intimal thickening is not evident. Note the small branch artery originating from the aorta. Epon embedded section stained with toluidine blue. $120 \times$

Fig. 2. Electron micrograph of the aorta from a 12 month old diabetic Chinese hamster. An endothelial lining cell contains an ovoid lipid droplet. The internal elastic lamella is a fairly homogeneous uniform structure separating the overlying endothelium from the underlying smooth muscle cells. $12,600 \times$

Fig. 3. A smooth muscle cell is present in the intima of the aorta and dark electron dense material and collagen fibers are seen. in the extracellular space of a diabetic hamster. $11,800 \times$ 

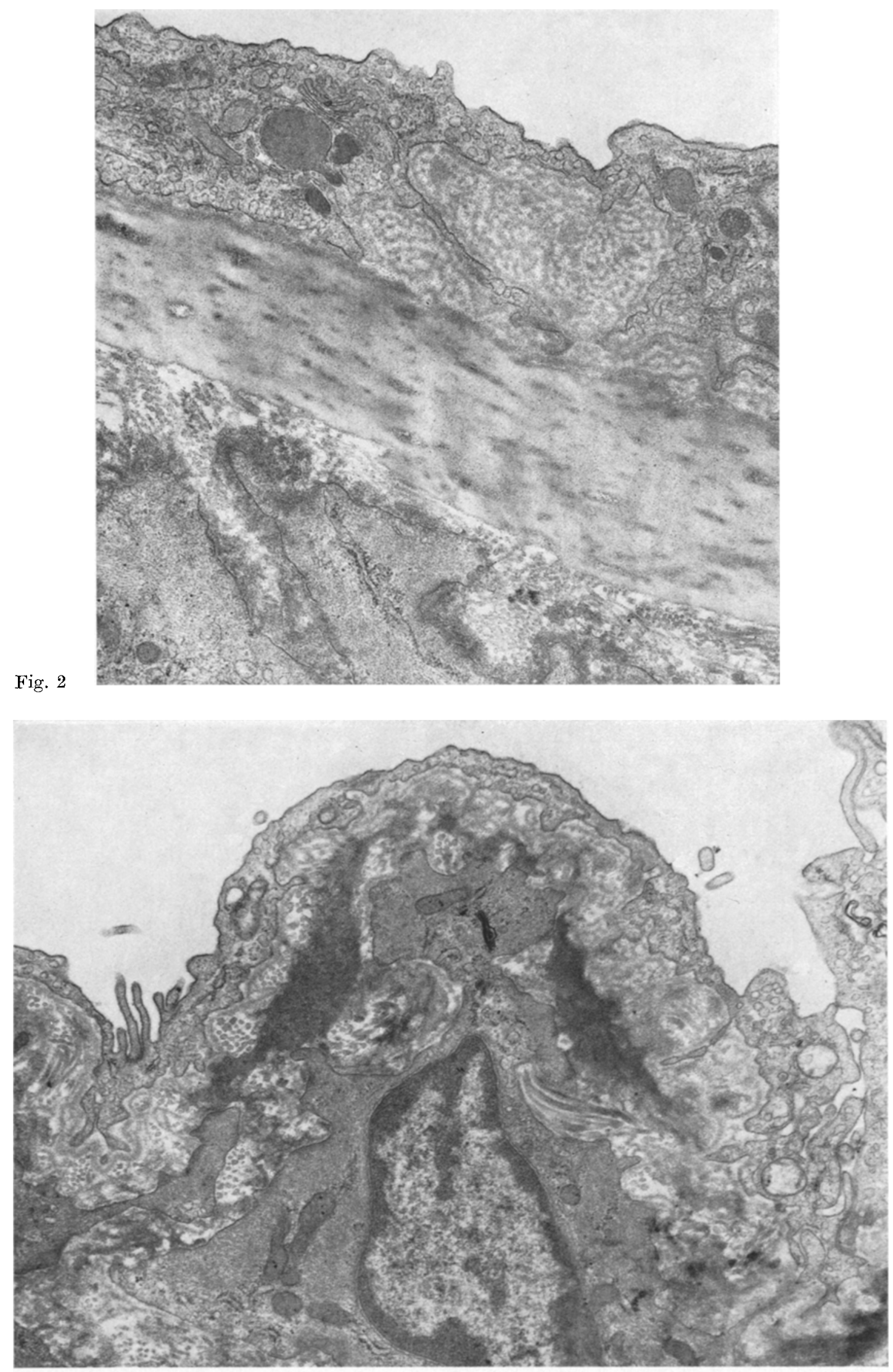

Fig. 3 


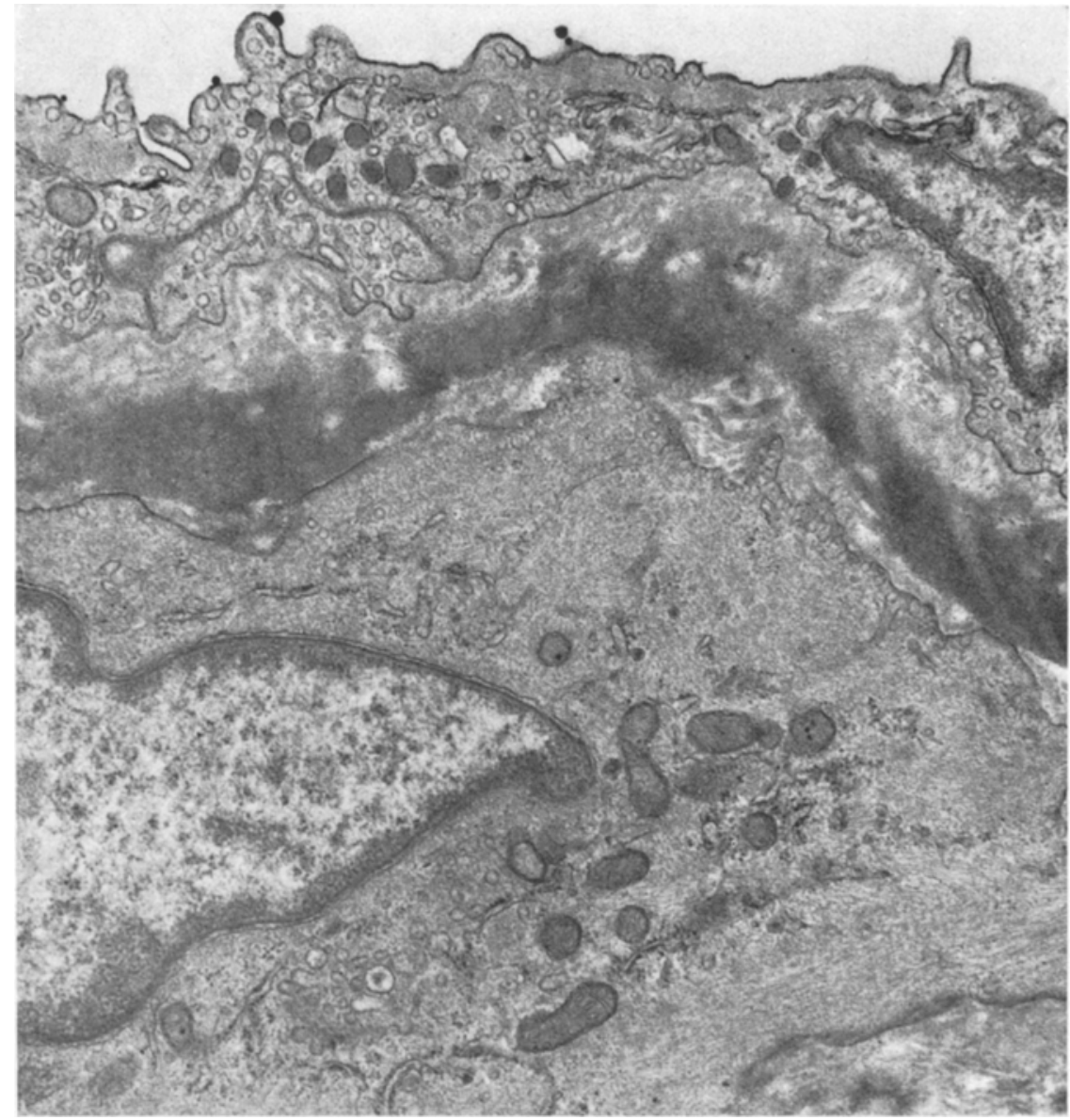

Fig. 4. Intima of the aorta containing a smooth muscle cell separated from the overlying endothelium by amorphous electron dense material in the extracellular space. 14,000 $\times$

gestive of fragmented internal elastic lamella or elastin, plus increased numbers of collagen fibers, were present in the adjacent extracellular space (Fig. 3). The intimal smooth muscle cells had normal appearing organelles and no increase in glycogen granules was evident (Fig. 4). On occasion, smooth muscle cells were identified in the intima of nondiabetic control animals but no electron dense amorphous material was present in the adjacent extracellular space and the internal elastic lamella was not fragmented or decreased in thickness. Diabetic hamsters frequently had calcium deposits in the media surrounded by collagen fibers and amorphous, pale staining material suggestive of ground substance (Fig. 5). In these areas the elastic lamellae were fragmented and smooth muscle cells or their cytoplasmic extensions were not evident (Fig. 5).

Diabetic animals had significantly elevated plasma glucose levels, ranging from 300 to $430 \mathrm{mg} \%$, decreased plasma insulin values, in the range of 11 to 12 $\mathrm{uU} / \mathrm{ml}$ except for one animal with a value of $130 \mathrm{uU} / \mathrm{ml}$, and urine samples for glucose and ketones were consistently $4+$ by Testape ${ }^{\circledR}$ and $4+$ by Ketostix ${ }^{\circledR}$ respectively. Total serum cholesterol values ranged from 232 to $400 \mathrm{mg} \%$.

Nondiabetic matched control animals did not have hyperglycemia or glycosuria. They showed no evidence of ketosis and their plasma insulin values were normal. They were considered normocholesterolemic having total serum cholesterol levels ranging from 141 to 196 $\mathrm{mg} \%$ except for one animal having a value of $297 \mathrm{mg} \%$.

\section{Discussion}

Atherosclerotic lesions that occur in large blood vessels of human diabetics are identified at an earlier age and are more extensive than lesions occurring in nondiabetics $[6,14]$, but no morphological differences have been described between them. Significant structural differences may not exist and well controlled studies of progressive changes in the larger arteries of young diabetics that might explain their predisposition to the development of atherosclerosis are not feasible.

Morphologic changes in small blood vessels of 


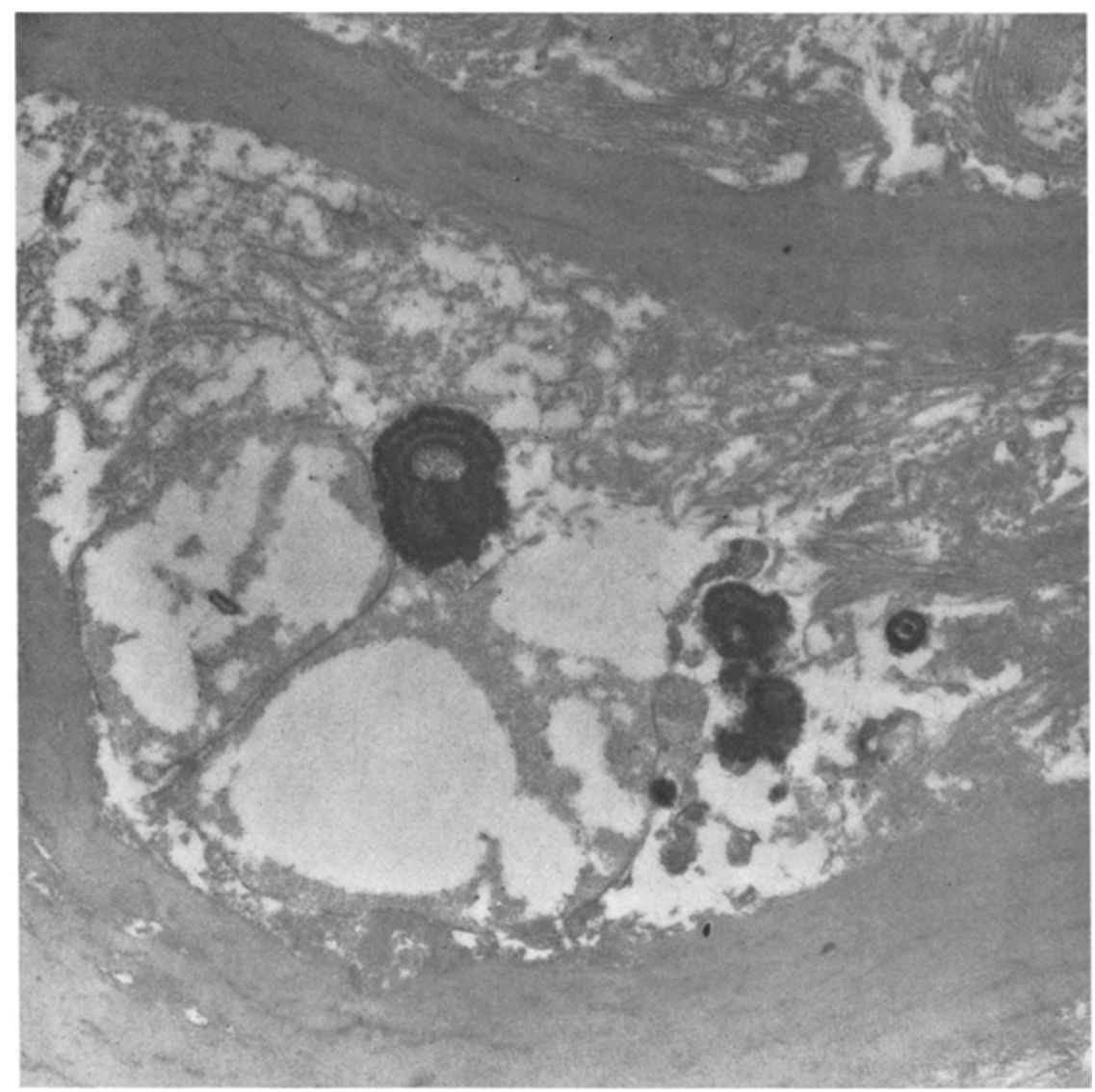

Fig. 5. Ovoid, dark staining, extracellular deposits are present in the media of the aorta in a diabetic animal. They are surrounded by collagen fibers and amorphous material in an area of apparent fragmentation of an elastic lamella. $18,000 \times$

human diabetics are well known. The electron microscopic findings consist of capillary basement membrane thickening and often reduplication [18]. Similar changes in fine structure consisting of basement membrane or lamina thickening have been described in the small vessels of the pancreas in the diabetic Chinese hamster [11].

Accordingly, the lesions described in the aorta of the diabetic Chinese hamster in this preliminary report may be similar to initial changes that occur in large arteries of humans with diabetes mellitus. Although the lesions described cannot be classified as atheroma, or even fatty streaks, they may represent significant alterations in the intima and internal elastic lamella that predispose the aorta to more extensive pathologic change.

Additional studies of more extensive aortic lesions, coronary artery, and small vessel changes are being undertaken and the effect of dietary lipid manipulation may provide additional significant data. The Chinese hamster represents an animal model that is excention-

\section{References}

1. Butler, L.: The inheritance of diabetes in the Chinese hamster. Diabetologia 3, 124-129 (1967)

2. Chobanian, A.V., Gerritsen, G.C.: Cholesterol metabolism in the diabetic hamster. J. clin. Invest. 50, 19a (1971)

3. Chobanian, A.V., Gerritsen, G.C., McCombs, H.L., Brecher, P.I.: Arterial lipid metabolism in diabetic animal models with reduced or elevated plasma insulin levels. In: Proceedings of the third international symposium on atherosclerosis, Berlin 1973. Berlin, Heidelberg, New York: Springer 1974 (In Press)

4. Federman, J.L., Gerritsen, G.C.: The retinal vasculature of the Chinese hamster: A preliminary study. Diabetologia 6, $186-191(1970)$

5. Gerritsen, G.C., Dulin, W.E.: Characterization of diabetes in the Chinese hamster. Diabetologia 3, 74$84(1967)$

6. LeCompte, P. M. : Vascular lesions in diabetes mellitus. J. chron. Dis. 2, 178-219 (1955)

7. Like, A.A., Chick, W.L.: Studies in the diabetic mutant mouse. II. Electron microseopy of pancreatic islets. Diabetologia 6, 216-242(1970) 
9. Like, A.A., Jones, E.E.: Studios on experimental diabetes in the Wellesley hybrid mouse. Diabetologia 3, $179-187(1967)$

10. Like, A.A., Miki, E.: Diabetic syndrome in sand rats. IV. Morphologic changes in islet tissue. Diabetologia $3,143-166(1967)$

11. Luse, S. A., Caramia, F., Gerritsen, G.C., Dulin, W.E.: Spontaneous diabetes mellitus in the Chinese hamster: An electron microscopic study of the islets of Langerhans. Diabetologia 3, $97-99$ (1967)

12. Morrison, A.D., Clements, R.S., Jr., Winegrad, A.I.: Effects of elevated glucose concentrations on the metabolism of the aortic wall. J. clin. Invest. 51, $3114-3123$ (1972)

13. Reynolds, E. S.: The use of lead citrate at high pH as an electron-opaque stain in electron microscopy. J. Cell Biol. 17, 208-212 (1963)

14. Robertson, W.B., Strong, J.P.: Atherosclerosis in persons with hypertension and diabetes mellitus. Lab. Invest. 18, 538-555 (1968)

15. Shino, A., Matsuo, T., Iwatsuka, H., Suzuoki, Z.: Structural changes of pancreatic islets in genetically obese rats. Diabetologia 9, 413-421 (1973)
16. Stout, R. W.: Insulin-stimulated lipogenesis in arterial tissue in relation to diabetes and atheroma. Lancet 1968 II, $702-703$

17. Stout, R.W., Bierman, E.L., Ross, R.: The arterial smooth muscle cell: Insulin stimulation of cell pro. liferation. In: Proceedings of the third international symposium on atherosclerosis, Berlin, 1973. Berlin, Heidelberg, New York: Springer-Verlag 1974 (In Press)

18. Vracko, R., Benditt, E.P.: Manifestations of diabetes mellitus. Their possible relationships to an underlying cell defect. Amer. J. Path. 75, 204-224 (1974)

19. Yalcin, S., Winegrad, A.I.: Defect in glucose metabolism in aortic tissue from alloxan diabetic rabbits. Amer. J. Physiol. 205, 1253-1259 (1963)

H. Louis McCombs, M.D.

Department of Pathology

Boston University School of Medicine

80 East Concord Street

Boston, Massachusetts 02118

USA 